OPEN ACCESS

Edited by:

Junji Xing,

Houston Methodist Research Institute,

United States

Reviewed by:

Eva Bartok

University Hospital Bonn, Germany Chaojie Wang,

The Ohio State University,

United States

*Correspondence:

Siew Kit Ng skng@usm.my

Specialty section: This article was submitted to Molecular Innate Immunity, a section of the journal

Frontiers in Immunology

Received: 03 November 2020 Accepted: 21 December 2020 Published: 03 February 2021

Citation:

Chiang DC, Li Y and Ng SK (2021) The Role of the Z-DNA Binding Domain in Innate Immunity and Stress Granules.

Front. Immunol. 11:625504. doi: 10.3389/fimmu.2020.625504

\section{The Role of the Z-DNA Binding Domain in Innate Immunity and Stress Granules}

\author{
De Chen Chiang ${ }^{1,2}$, Yan $\mathrm{Li}^{3}$ and Siew Kit $\mathrm{Ng}^{1,3^{*}}$ \\ ${ }_{1}$ Advanced Medical and Dental Institute, Universiti Sains Malaysia, Kepala Batas, Malaysia, ${ }^{2}$ School of Pharmaceutical \\ Sciences, Universiti Sains Malaysia, Gelugor, Malaysia, ${ }^{3}$ Department of Biology, Southern University of Science and \\ Technology, Shenzhen, China
}

Both DNA and RNA can maintain left-handed double helical Z-conformation under physiological condition, but only when stabilized by Z-DNA binding domain (ZDBD). After initial discovery in RNA editing enzyme ADAR1, ZDBD has also been described in pathogen-sensing proteins ZBP1 and PKZ in host, as well as virulence proteins E3L and ORF112 in viruses. The host-virus antagonism immediately highlights the importance of ZDBD in antiviral innate immunity. Furthermore, Z-RNA binding has been shown to be responsible for the localization of these ZDBD-containing proteins to cytoplasmic stress granules that play central role in coordinating cellular response to stresses. This review sought to consolidate current understanding of Z-RNA sensing in innate immunity and implore possible roles of Z-RNA binding within cytoplasmic stress granules.

Keywords: Z-DNA binding domain, Z-RNA, innate immunity, stress granules, ADAR1, ZBP1, E3L, PKZ

\section{INTRODUCTION}

\section{Z-DNA/Z-RNA and Z $\alpha$ Domain}

The structure of double-stranded DNA (dsDNA) in nature can be broadly categorized into 3 major forms, namely compact right-handed A-DNA, loose right-handed B-DNA and the unique lefthanded Z-DNA conformation. Unlike the anti-conformation base arrangement throughout A- and B-DNA, the nucleoside bases in Z-DNA adopt alternating syn- and anti-conformation bases, giving rise to its distinctive left-handed double helical structure with zigzag backbone (thus its name) (1). The X-ray crystal structure of dsDNA in Z-conformation was first observed in the 1980s under high salt condition $(15 \mathrm{mM} \mathrm{MgCl} 2)(2,3)$. However, it is only after the discovery of the first Z-DNA binding domain (ZDBD) in Adenosine Deaminase Acting on RNA 1 (ADAR1) protein almost two decades later that implied physiological-relevance of Z-DNA (4). Since then, innumerable studies were done to identify ZDBD in other proteins, and characterize the role of these ZDBD-containing proteins in gene regulation, innate immunity, cancer, and autoimmunity disease (5-8). Similar to dsDNA, double-stranded RNA (dsRNA) can also adopts the Z-conformation (9). Indeed, both ZRNA and Z-DNA can be stabilized by the first ZDBD of ADAR1, where resolved crystal structure revealed nearly identical protein-nucleic acid interactions for both Z-RNA and Z-DNA to form thermodynamically stable complexes (10-12). Therefore, it is widely assumed that Z-RNA interacts with ZDBDs in a similar manner to Z-DNA. 
Under normal physiological conditions, Z-DNA/Z-RNA exist at higher energy configuration and thus are energetically unstable on their own, except when in binding with ZDBDs (13). The highly conserved ZDBD likely arise from a sub-group of winged HelixTurn-Helix (wHTH) motif common in most prokaryotic DNAbinding proteins (13). In alignment with review article by Rich and Zhang, 2003 (1), ZDBDs that can form quasi-stable interaction with Z-DNA/Z-RNA will be referred to as the Z $\alpha$ domain, whereas homologous ZDBD that cannot will be mentioned as the $Z \beta$ domain, within this review. The $Z \alpha$ domain is highly-conserved, where the amino acid residues within the binding pocket primarily interacts with the zigzag sugar-phosphate backbone of Z-DNA/ZRNA, which contributes to high specificity and affinity for Z-DNA/ Z-RNA $(10,13,14)$. Structural analysis revealed the binding preference of $Z \alpha$ domain to CG-repeat sequences, $d(C G)_{n}$ (15). That said, some non-CG-repeat with similar structural features, $\mathrm{d}$ $(\mathrm{CACGTG})_{2}, \mathrm{~d}(\mathrm{CGTACG})_{2}$ and d(CGGCCG $)_{2}$, have also been reported to bind to $Z \alpha$ domain (16). Numerous attempts to map Z-DNA formation in the nucleus had suggest its involvement in transcriptional regulation, but similar mapping data about Z-RNA is lacking $(17,18)$.

Since the initial discovery of $Z \alpha$ domain in ADAR1, Z-DNA/ZRNA binding has been thought to be involved in mediating innate immunity, as Z $\alpha$ domain is only present in the interferon-inducible ADAR $1_{\mathrm{p} 150}$ isoform, instead of the constitutively expressed $\operatorname{ADAR}_{\mathrm{p} 110}$ isoform $(19,20)$. In addition to mammalian ADAR1, $Z \alpha$ domains were subsequently discovered to be encoded in proteins across different classes of metazoans, including immunity-related ZDNA Binding Protein 1 (ZBP1) in mammals (21) and Protein Kinase Containing Z-DNA binding domains (PKZ) in fishes (22); and viruses affecting them, such as E3L in poxviruses (23), and ORF112 in fish herpesviruses (24). RBP7910 is recently discovered in kinetoplastids as another ZDBD-containing protein (25). The recurring theme of $Z \alpha$ domains conservation within host immune proteins and pathogen proteins is highly indicative of the involvement of $\mathrm{Z} \alpha$ domains in host immune regulation, against viral infections and/or in cancer and auto-immunity.

In this review, we focused on the current understanding for the role of $Z \alpha$-containing proteins in innate immunity and posttranscriptional regulations, through their interaction with cytosolic Z-RNA.

\section{Antiviral Innate Immunity}

Antiviral innate immunity generally refers to the initial programmed broad-spectrum cellular reaction following identification of viruses or their components. In a nutshell, the acute antiviral response starts with the sensing of virusassociated molecular patterns (VAMPS), followed by the cascading signaling events culminating in the activation of type I interferon response. Various host sensor proteins such as Tolllike receptors (TLRs), retinoic acid inducible gene- I (RIG-I)-like receptors (RLR), and Nod-like receptors (NLR) can recognize a vast range of viral nucleic acids or other VAMPS upon virus infection (26-28). These interactions kickstart the IRF3/7-, NF$\kappa \mathrm{B}$-mediated signalling cascades towards the establishment of antiviral state in the infected and surrounding cells. The synthesis and secretion of type I interferons (IFN), IFN- $\alpha$ and
IFN- 3 , are of central importance in acute antiviral response (29, 30). Type I IFNs raise alarm in neighboring cells when bound to their IFN- $\alpha / \beta$ receptors (IFNARs) (31), which in turn activate the Janus kinase (JAK)-Signal transducer activator of transcription (STAT) pathway (32). Phosphorylated STAT1 and STAT2, together with IRF9 (33), forms the Interferon Stimulatory Gene Factor 3 (ISGF3), a potent transcriptional activator of hundreds of interferon-stimulated genes (ISGs) $(34,35)$. The ISG protein effectors directly target viral functions and pathways to inhibit viral entry, translation, replication and egress; or promote intercellular communication to enhance pathogen sensing; or facilitate the resolve to cellular homeostasis during post-infection $(36,37)$. Persistent virus infection beyond the acute phase would lead to activation of virus-specific adaptive immune response, through IFNs and other pro-inflammatory cytokines (38).

\section{Stress Granules}

Cellular stress occurs when the ability to maintain homeostasis balance within a cell is affected. Various factors including viral invasion, heat shock, oxidative stress, nutrient deprivation, DNA damage, can trigger stress response, where cell survival is dependent on successful resolution of the cellular stresses (39). Upon stress onset, cells will rapidly arrest their translational machinery and stall their protein synthesis (40). These arrested messenger ribonucleoproteins (mRNPs) will aggregate into multiple non-membranous foci in the cytoplasm, known as stress granules (SGs). The composition of SGs consists of ribosomal components, mRNA, structural proteins, and many signaling proteins (41). In addition, nucleocytoplasmic transport is also disrupted through recruitment of essential nucleocytoplasmic transport factors, including Ran GTPase, nucleoporins and karyopherins to SGs (42).

While initially assumed to be passive repositories of untranslated mRNA, SGs are now thought as RNA triage sites where mRNA transcripts were actively sorted towards decay, storage, or translation reinitiation (43). SGs function as vital signaling hubs in coordinating cellular processes during stress response, from selective translation of vital proteins against stress conditions, moderating metabolism, suppressing apoptosis, to antiviral response (44-46). Attempts to catalogue protein components within mammalian SGs suggests that many signaling and regulatory proteins moved in and out of SGs in spatiotemporal manner $(47,48)$. That said, there are some notable SGs markers including T-cell intracellular antigen 1 (TIA-1), TIA-1-related protein (TIAR), Ras GTPase-activating protein-binding protein $1(\mathrm{G} 3 \mathrm{BP} 1)$ and poly(A)-binding protein 1 (PABP1).Upon resolution or sufficient adaptation to the stress, step-wise dissolution of SGs allows stored mRNPs to quickly reform the translational assembly, therefore facilitating rapid recovery of protein translation in the cells (49).

The phosphorylation of translation initiation factor (eIF2 $\alpha$ ) by eIF $2 \alpha$ kinases catalyses the formation of SGs through stalling of the initiation of ribosomal translation. The recycling of inactive eIF $2 \alpha$-GDP to active eIF $2 \alpha$-GTP is inhibited by eIF $2 \alpha$ phosphorylation, thereby disrupting the formation of the essential translation initiator, e IF $2 \alpha-G \mathrm{~T} P-\operatorname{tRNA} A_{i}^{\mathrm{Met}}$ (50). The 
eIF2 $\alpha$ kinases are activated under different stress conditions, for example PKR is activated by dsRNA, PERK by endoplasmic reticulum stress, while $\mathrm{HRI}$ and GCN2 is responsible for oxidative and nutrient stress respectively (51).

A recent excellent review has highlighted the role of SGs in antiviral response, notably on the mechanisms of viral translational inhibition and counteracting strategies adapted by viruses (46).SGs formation effectively arrests viral replication by sequestering viral mRNA into SGs from protein translation (27, 52). Intriguingly, while several viruses evolved various mechanism to inhibit SGs formation, such as promoting cleavage of G3BP1 (53), inhibiting PKR phosphorylation (54), or sequestering SGs core proteins $(55,56)$; others hijack the SGs formation to prioritize viral protein synthesis $(57,58)$.

\section{ZDBD-CONTAINING PROTEINS}

\section{Adenosine Deaminase Acting on RNA 1 (ADAR1)}

ADAR1 is a member of the Adenosine deaminase, RNA-specific (ADAR) protein family, where their adenosine-to-inosine (A-toI) RNA editing activity is responsible for a wide range of regulation in gene expression, peptide modification in nervous system, RNA interference (RNAi), protein activation or inhibition (59). A-to-I dsRNA editing alters stable canonical $\mathrm{U}$-A base pairing to U-I wobble, destabilizing the edited target dsRNA duplex conformation and compromising its functionality (60). In addition, ADAR1-mediated RNA editing activities are also responsible for a subset of cancer and tumour development (61), for instance, in gastric (62), cervical (63), breast (64), thyroid (65), liver (66) and colorectal cancers (67). The general structures of ADAR proteins consist of a deaminase domain at the C-terminal, and dsRNA binding domains (dsRBD). In addition, the human ADAR1 has extra N-terminal ZDBDs, a unique feature otherwise absents in ADAR2 and ADAR3 (Figure 1). There are two major ADAR1 isoforms; where ADAR $1_{\mathrm{p} 150}$ is only induced by type I interferons and is mostly cytoplasmic, whereas the constitutively expressed ADAR $1_{\mathrm{p} 110}$ is localized in the nucleus $(68,69)$. This distinct localization of ADAR1 isoforms is attributed to the presence of a bipartite Nuclear Export Signal (NES) located within the $\mathrm{ADAR}_{\mathrm{p} 150}$-exclusive $\mathrm{Z} \alpha$ domain, while the Nuclear Localization Signal (NLS) is within the common dsRBD region (70).

ADAR1 has been implicated as a master regulator of the innate immunity, largely through its A-to-I editing activity to avoid unwarranted deleterious effects (71-73). ADAR1 knockout studies showcased the vital regulatory role of $A D A R 1_{\mathrm{p} 150}$ in antiviral immune homeostasis and autoimmunity, through MDA5-MAVS sensing pathway (74), NF- $\kappa \mathrm{B}$ gene regulation pathway (75) and PKR-mediated apoptosis (76) (Figure 2). Editing on ubiquitous self RNA such as Alu transcripts prevents recognition by cytosolic dsRNA sensor MDA5 and erroneous autoimmune response $(77,78)$. Meanwhile, A-to-I editing can disrupt both the viral translational and replication process by compromising the structural integrity and genetic consistency of virus RNA (79). Direct suppressive effect on viral replication by ADAR1 were observed in hepatitis C (HCV) (80) and hepatitis B (HBV) (81). On the other hand, numerous viruses have evolved to hijack ADAR1's editing activity to as

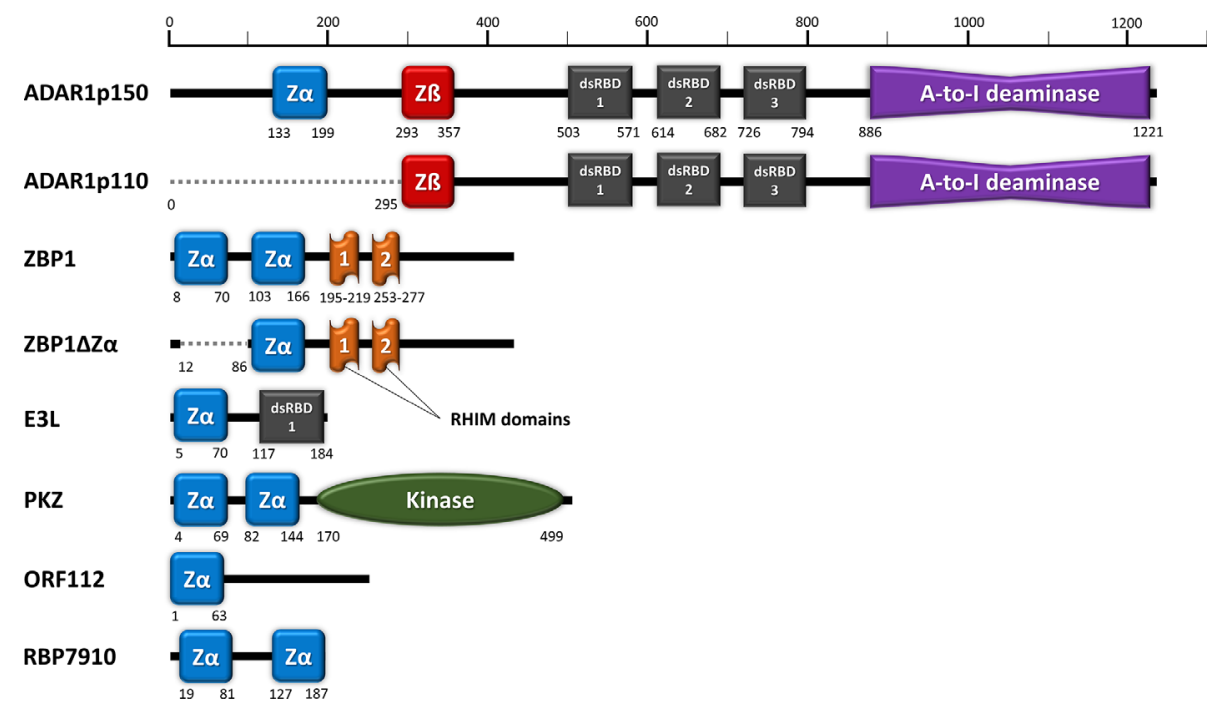

FIGURE 1 | Domain organization of ZDBD-containing proteins: ADAR1, ZBP1, E3L, PKZ, ORF112, and RBP7910. Z $\alpha$ domain (blue) denotes ZDBD that can bind Z-DNA/Z-RNA, while ZB domain (red) denotes ZDBD that cannot bind Z-DNAZZ-RNA. ADAR1 ${ }_{\mathrm{p} 150}$ harbors an extra Z $\alpha$ domain compared to ADAR1 ${ }_{\mathrm{p} 110}$, while sharing identical dsRNA binding domains (dsRBDs) and catalytic deaminase domain. Two natural isoforms were also described for ZBP1, where ZBP1Z $\triangle$ does not contain the first Z $\alpha$ domain present in full length ZBP1. Vaccinia virus E3L vital for its pathogenicity contains a single Z $\alpha$ domain and a dsRBD. Fish PKZ contains two N-terminal Z $\alpha$ domains as the RNA recognition motifs, in addition to a C-terminal kinase domain. On the other hand, the ORF112 protein identified from fish herpesvirus only has a single Z $\alpha$ domain at its amino-end. Most recently, trypanosome RBP7910 protein has been reported to contain two Z $\alpha$-like domains, although further characterization of their function may be necessary. 
immune evasion strategy, since A-to-I editing of their RNA can avoid the innate immune sensing (82). The immune suppressive ability of ADAR1 were exploited by measles virus (83), hepatitis delta virus (HDV) (84), Human Immunodeficiency Virus (HIV) (85) and Kaposi's sarcoma-associated herpesvirus (KSHV) (86). For Human T-cell leukaemia virus type 1 (HTLV-1) (87) and dengue virus (DENV) (88), only overexpression of the cytoplasmic $A D A R 1_{p 150}$, but not $A D A R 1_{p 110}$, had proviral effect.

The exact role of the exclusive $Z \alpha_{\mathrm{ADAR} 1}$ in $A D A R 1_{\mathrm{p} 150}$ has only been slowly unravelled in recent years. Rare Mendelian autoimmune disorders like Aicardi-Goutières syndrome (AGS) and Bilateral Striatal Necrosis/Dystonia (BSD) have been attributed to ADAR1 dysfunction. Genetic profiling of Adar1 gene among these patients showed that loss-of-function mutation at $Z \alpha_{A D A R}$ causes the hallmark type I interferonopathy, suggesting that Z-DNA/Z-RNA binding is important to prevent dysregulated interferon response (89). In addition, $Z \alpha_{A D A R 1}$ is found to be responsible for localization of ADAR $1_{\mathrm{p} 150}$ to SGs under oxidative and interferon-induced stress $(90,91)$ (Figure 2$)$. In contrast, $A D A R 1_{\mathrm{p} 110}$ lacking the $\mathrm{Z} \alpha_{\mathrm{ADAR} 1}$ does not localize to SGs (91) (Figure 1). Only mutation to key interacting residues at the binding pocket of $Z \alpha_{\mathrm{ADAR} 1}$ affects the localization to SGs, showing that Z-RNA binding is indeed important (91). Z-RNA binding ability is essential in $\mathrm{Z}_{\mathrm{ADAR}^{-}}$ ribosome interaction, which leads to translational inhibition (92). On the other hand, ADAR1-kd cells exhibit an increase in SGs formation following virus infection or IFN-treatment, suggesting inhibitory role of ADAR1 on SGs formation (93).This is in line with the general observation whereby ADAR1 functions as a suppressor of type I interferon response, including inhibiting the PKR phosphorylation precluding SGs formation (77). Enhanced editing ability has been described on dsRNAs that more readily adopt $\mathrm{Z}$-conformation, where Z-RNA binding could alter the selectivity of ADAR1-editing site and dsRNA substrates (94).

\section{Z-DNA-Binding Protein 1 (ZBP1)}

Z-DNA-binding protein 1 (ZBP1), alternatively known as DNAdependent activator of IFN-regulatory factors (DAI) or Tumor stroma and activated macrophage protein (DLM1), plays a significant role in innate immune response against viruses or other non-self-agents (95). ZBP1 has two conserved N-terminal $\mathrm{Z} \alpha$ domains, and two receptor-interacting protein homotypic interaction motif (RHIM) domains (Figure 1). The presence of only $Z \alpha$ domains as nucleic-acid recognition domains suggests the primary role of ZBP1 as a cytosolic sensor for Z-DNA/ZRNA. Activation of ZBP1 then leads to downstream signal transduction mediated through the RHIM domain interactions with receptor-interacting protein (RIP) kinases, regulating apoptosis, inflammation, and interferon responses to pathogens $(95,96)$. In addition, ZBP1 sensing activates NLRP3 inflammasome complex that leads to PAN-optosis (pyroptosis, apoptosis, and necroptosis) process (97) (Figure 2). In mice model, knocking out ZBP1 is sufficient to ameliorate IFN- $\gamma$ - and TNF-induced acute systemic inflammatory response syndrome (SIRS), which demonstrates its involvement in IFN-induced necroptosis (98). ZBP1-knockout mice exhibited remarkably reduced inflammatory responses and epithelial damage than the wild type mice upon influenza A virus infection, suggesting the essential role of ZBP1 in PAN-optosis pathways (99). ZBP1 deletion significantly increased the mortality rate in mice when infected with West Nile virus (WNV) and Zika virus (ZIKV) (100). ZBP1 has also been implicated IL-17-mediated skin inflammation (101) and regulation of stem cell differentiation (102).

$\mathrm{X}$-ray crystallographic study has revealed significant ZRNA/Z-DNA binding affinity for both first and second $Z \alpha_{Z B P 1}$ (103). Somewhat confusingly, only the first $Z \alpha_{Z B P 1}$ is essential for the localization of ZBP1 to cytoplasmic SGs under heat, arsenite and interferon-induced stress (91, 104). Meanwhile, a prominent alternatively-spliced ZBP1 variant without the first $Z \alpha$ domain $(Z B P 1 \Delta Z \alpha 1)$ does not localize to SGs (104) (Figure 1). Interestingly, the ZBP1 $\Delta \mathrm{Z} \alpha 1$ variant forms aggregates in untreated cells that disassemble upon heat shock or arsenite treatment, in a total contrast to full length ZBP1. The Z-RNA generated from anti-sense Influenza A virus (IAV) triggers RIPK3-MLKL-mediated necroptosis, where nuclear envelope collapse in infected cells leads to cell death and neutrophil recruitment (105). In another study, the second $Z \alpha_{Z B P 1}$ is found to be essential for influenza-induced PAN-optosis (106). For Herpes simplex virus (a DNA virus), ZBP1-mediated necroptosis is thought to be activated through interaction with viral RNA transcripts, instead of viral DNA (107).

\section{Protein E3 (E3L) of Poxvirus}

Intriguingly, the poxvirus E3L protein reportedly vital for the virulence and host range factor, viral pathogenesis, and antagonizing host innate immunity, also contains $Z \alpha$ domain (23). The E3L protein suppresses cytokines-mediated inflammation through both PKR-dependent and PKRindependent pathways; in which $\mathrm{p} 38$ and NF- $\mathrm{KB}$ activation is inhibited, and IL- 6 and IFN- $\beta$ production ameliorated, respectively (108). The 184 amino acid long E3L protein harbours two distinct RNA binding motifs, a conserved $\mathrm{Z} \alpha$ domain at $\mathrm{N}$ terminal and a dsRBD at the C-terminal (Figure 1). Both domains work synergistically to suppress immune response to poxvirus infection, although the mechanism is not entirely clear. The phosphorylation of antiviral transcription factors IRF3 and IRF7 can be effectively inhibited by E3L without PKR-dsRNA interactions (109). Interestingly, mutational analysis revealed that dsRNA binding activity is not necessary for antagonistic role of E3L protein for PKR inhibition, cytokine suppression and apoptosis (110). Antiviral factor ISG15 inhibition requires the dsRBD to block type I interferon (IFN) induction (111), however, $Z \alpha_{\mathrm{E} 3 \mathrm{~L}}$ is imperative for full IFN and PKR inhibition $(112,113)$.

$Z \alpha_{\mathrm{E} 3 \mathrm{~L}}$ exhibits high structural resemblance to those of ADAR1 and ZBP1, and is capable of Z-DNA/Z-RNA binding. Indeed, the $Z \alpha_{A D A R 1}$ and $Z \alpha_{Z B P 1}$ can functionally replace $Z \alpha_{\mathrm{E} 3 \mathrm{~L}}$ without affecting the viral pathogenicity of E3L protein (114). Therefore, $Z \alpha_{\mathrm{E} 3 \mathrm{~L}}$ likely plays a role in competitive inhibition for Z-DNA/Z-RNA binding antagonizing the function of $A D A R 1_{p 150}$ and $Z B P 1$ during virus infection (114). The $Z \alpha_{\mathrm{E} 3 \mathrm{~L}}$ 


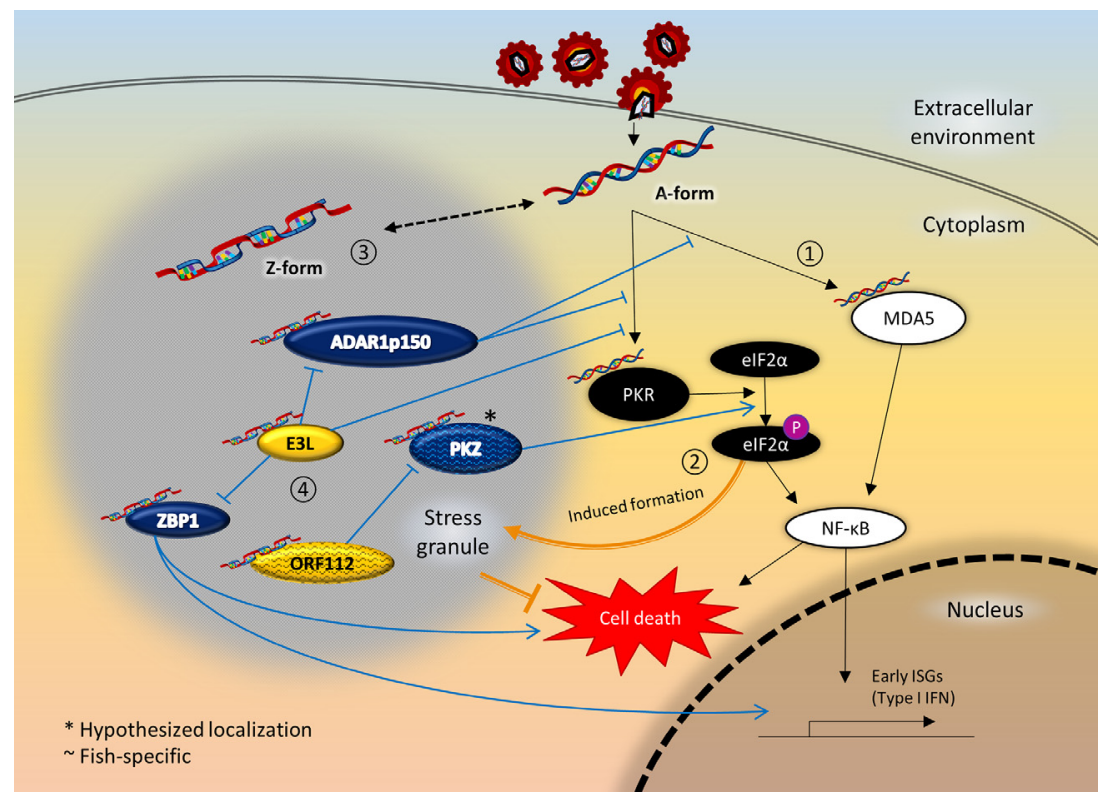

FIGURE 2 | Crosstalk between ZDBD-containing proteins, stress granules, and innate immunity signaling pathway following RNA virus infection. 1) Innate immune sensors like MDA5 and PKR are activated upon recognition of virus RNA in the cytoplasm, which in turn activates the NF-kB pathway culminating in expression of type I IFN. 2) At the same time, activated PKR also phosphorylates elF2 $\alpha$, causing stalled mRNA translation that induce the formation of stress granules. Stress granules are instrumental in promoting cell survival under cellular stresses like virus infection. 3) Most ZDBD-containing proteins have been shown to localize to stress granules, mediated via respective $Z \alpha$ domains. Therefore, it is possible that RNA can adopt Z-conformation more readily within stress granules. 4 ) ADAR1 150 is a negative regulator of immune response protecting against autoimmunity and chronic inflammation, as edited RNA transcripts lose immunogenicity. On the other hand, ZBP1 activation triggers IFN response and cell death mechanism. The vaccinia virus E3L is an inhibitory protein towards the antiviral response of its mammalian host, which is dependent of its Z $\alpha$ domain. In fish, PKZ is a paralog that complements PKR-mediated pathways, as PKZ can be activated by Z-RNA binding. The cyprinid herpesvirus ORF112 protein antagonizes the activation of PKZ as the virus immune evasion strategy. Incidentally, PKR and MDA5 had also been reported to localize to stress granules. It is therefore plausible that the close proximity through localization to stress granules facilitate the crosstalk between ZDBD-containing proteins and immune recognition and signaling pathways.

is responsible for suppressive effects in toll-like receptor (TLR) activation and host immune response against vaccinia virus infection (115). A recent study directly demonstrated $Z \alpha_{\mathrm{E} 3 \mathrm{~L}}$ as a competitive inhibitor with ZBP1, whereby the masking of putative Z-DNA/Z-RNA prevents RIPK3-mediated necroptosis (116) (Figure 2).

Consistent with $\mathrm{ADAR}_{\mathrm{p} 150}$ and $\mathrm{ZBP} 1$, the $\mathrm{Z} \alpha_{\mathrm{E} 3 \mathrm{~L}}$ is also responsible for its localization to mammalian SGs, mediated via functional Z-RNA binding (91) (Figure 2). Indeed, vaccinia virus mutant lacking E3L causes elevated SGs assembly, translational arrest, and reduced viral replication within the mammalian cells (117).

\section{Protein Kinase Containing Z-DNA Binding Domains (PKZ)}

$\mathrm{PKZ}$ is an immune modulator protein initially discovered in fishes as a paralog to PKR (118-120). PKZ shares a similar Cterminal catalytic domain with PKR, but differs at the N-terminal RNA binding region. PKZ harbours two Z $\alpha$ domains at its $\mathrm{N}$ terminal, instead of two dsRBDs in PKR (Figure 1). Although both PKR and PKZ have independent sensing mechanism for dsRNA and Z-form nucleic acids, these proteins demonstrate a cooperative role in host response against viral infection (121). The conservation of PKZ among fishes suggests expanding the pathogen- or danger-associated molecular patterns (PAMPs/ DAMPs) recognition is important for fish immunity and survival (122). Similarly to PKR, PKZ can initiate apoptosis via eIF2 $\alpha$ phosphorylation in viral-infected cells as part of its antiviral role (8) (Figure 2). Significant interactions were observed through coimmunoprecipitation assays between cytosolic PKZ with other IFN immune mediators like IRF3, IRF9 and STAT2, illustrates the vital role of PKZ in inducing fish's IFN response (123). A recent review details the role of PKZ within the type I interferon response of fish innate antiviral immunity (118).

Functional analysis revealed PKZ can only be activated by ZDNA/Z-RNA binding, instead of poly(I:C) - a common viral dsRNA mimic (124) (Figure 2). Circular dichroism spectroscopy of the Z $\alpha_{\text {PKZ }}$ reported similar Z-DNA-binding affinity and facilitate efficient B-to-Z transition of bound nucleic acid ligand, in close correspondence to those interferon-inducible mammalian ZDBD-containing proteins described above (119, 125-127).

\section{Open Reading Frame 112 Protein (ORF112) of Cyprinid herpesvirus 3}

The ORF112 protein of Cyprinid herpesvirus 3 (CyHV3), a major koi herpesvirus infecting common carp, contains an $\mathrm{N}$-terminal 
Z $\alpha$ domain (128) (Figure 1). ORF 112 of $C y H V 3$ is important in suppressing type I interferon response in infected teleost fishes, in comparison to spring viremia when infected with Rhabdovirus SVCV (129). This discovery of ZDBD in fish viruses immediately suggests host-pathogen antagonism with PKZ akin to ZBP1-E3L previously described in mammals. Indeed, the $Z \alpha_{\mathrm{ORF} 112}$ protein binds Z-DNA/Z-RNA in left-handed conformation resembles that of ADAR1, ZBP1, PKZ and E3L despite of low overall sequence identity and different binding kinetics (128). Significant structure resemblance between $\mathrm{Z} \alpha_{\mathrm{ORF112}}$ with $\mathrm{Z} \alpha_{\mathrm{PKZ}}$ suggests common ancestry or convergent evolution as a competitive inhibitor for PKZ sensing (24) (Figure 2).

In line with other ZDBD-containing proteins discussed so far, ORF112 also localizes to SGs during oxidative stress (24) (Figure 2).

\section{RNA-Binding Protein 7910 (RBP7910) of Trypanosoma brucei}

A recent study discovered that RBP7910 from Trypanosoma brucei is a ZDBD-containing protein, whereby one ZDBD-likedomain was each reported at its $\mathrm{N}$ - and C-terminal respectively (25) (Figure 1). Trypanosoma brucei is a human-fly parasite that can cause African Trypanosomiasis or "sleeping sickness". RBP7910 is a mitochondrial protein involved in RNA editing complexes in kinetoplastids (130). A protein sequence-based search for functional domains led to the prediction of the ZDBD-like domains, where key residues involved in Z-DNA/ Z-RNA binding for Z $\alpha$ domain has been conserved. Nonetheless, mutational studies on these residues in RBP7910 led to lowerthan-expected reduction in Z-DNA/Z-RNA-binding affinity compared to those reported for $Z \alpha_{A D A R 1}$ (25). Further studies are needed to verify the function of ZDBD within RBP7910.

\section{PERSPECTIVES}

\section{Z-DNA/Z-RNA Recognition in Antiviral Immunity}

$\mathrm{Z} \alpha_{\mathrm{ADAR} 1}$ is only present in the ADAR $1_{\mathrm{p} 150}$ isoform but not in the shorter $\mathrm{ADAR} 1_{\mathrm{p} 110}$ isoform (Figure 1). An alternative transcription start site is favoured when Interferon Stimulatory Response Element (ISRE) at promoter region is bound by ISGF3, thereafter catalyst for the splicing event leading to $Z \alpha$ containing-ADAR $1_{\mathrm{p} 150}$ expression (131). Similarly, other ZDBD-containing host proteins ZBP1 and PKZ are also ISGs whose expression is modulated through type I interferons (132, 133). These indicate the involvement of Z-RNA binding in the cellular regulatory events following virus infection. Furthermore, the identification of $Z \alpha$ domain(s) in antagonistic virus proteins reaffirms the importance of Z-RNA recognition in immune regulation $(24,116)$.

Fluorescence study on B-to- $Z$ transition dynamics proposed an interesting theory on Z-DNA/Z-RNA formation (134). The study demonstrated dynamic formation of single molecule ZDNA prior to stabilization by $Z \alpha$ domain, instead of induction caused by protein-nucleic acid interaction. This suggests that $Z \alpha$ domain function by recognizing the existing transient form of ZDNA/Z-RNA, rather than a forced conformation change upon binding with canonical B-form dsRNA. For ADAR $1_{\mathrm{p} 110}$, cooperative binding between three dsRBDs give rise to selectivity of A-to-I editing sites (135) (Figure 1). The additional $Z \alpha_{\mathrm{ADAR} 1}$ present only in $\mathrm{ADAR} 1_{\mathrm{p} 150}$ can thus give rise to different editing sites during antiviral response (94) (Figure 1). Furthermore, alternating transition in conformation between B-form and Z-form within a dsRNA may lead to multiple editing sites on the same dsRNA, an observation described as hyperediting (136). ADAR1 1 p150 is thought to effectively negate the initiation of interferon response by editing dsRNA to prevent MDA5 and PKR sensing $(71,77,87,137)$ (Figure 2). In contrast to $A D A R 1_{p 150}$, there are two functional Z $\alpha$ domains in both ZBP1 and PKZ (Figure 1). These $Z \alpha$ domains are the only known nucleic acid recognition domains in respective proteins, and possibly behave synergistically for Z-DNA/Z-RNA binding. ZBP1 and PKZ function as instigators of immune response through sensing of viral nucleic acids following virus infection, via downstream signaling $(95,121)$ (Figure 2). The transient nature of ADAR $1_{\mathrm{p} 150}$ binding with Z-RNA for editing activity, in contrast to the Z-RNA-dependent activation of ZBP1 and $P K Z$, could in part explain the difference in the $Z \alpha$ domains setup in these ZDBD-containing proteins. Collectively, all point towards the indispensable role of $Z \alpha$ domain as PAMPs/DAMPs sensor of Z-RNA, particularly in regards to antiviral defense.

\section{Z $\alpha$-Mediated Localization to Stress Granules}

Interestingly, most ZDBD-containing proteins $\left(A D A R 1_{\mathrm{p} 150}\right.$, ZBP1, E3L, ORF112) have been independently reported to localize to SGs during cellular stresses $(24,90,91,104)$ (Figure 2). Though not explicitly verified, $P K Z$ is also expected to localize to SGs in the same manner as ORF112, its inhibitory protein. The localization of ZDBD-containing proteins to SGs is mediated through Z-RNA binding by respective Z $\alpha$ domains, as mutations to key interaction residues abolished the localization pattern (91). This discovery identified a novel role of $\mathrm{Z} \alpha$ domain at the forefront regulating the cellular fate and response to virus infections, and other stresses. Nevertheless, the Z-RNA substrate in SGs has not been elucidated so far owing to difficulties in complete isolation of SGs. It is also entirely plausible that favorable conditions for B-to-Z transition and Zlike steps primarily arises in the SGs, in which case the ZDBDcontaining proteins is sequestered in SGs through $\mathrm{Z} \alpha$-mediated Z-RNA binding (138). Intriguingly, many proteins involved in IFN-mediated antiviral response like RIG-I, MDA5, PKR, OAS1, TRIM25 have also been found in SGs $(46,47)$. This sequestration may be unspecific as some are RNA binding proteins or known interaction partners. However, co-localization to SGs may enhance interactions otherwise not favorable between ZDBDcontaining proteins and these antiviral sensor and effector proteins. For instance, immunoprecipitation assay revealed that PKR interacts with ADAR1 via dsRNA bridge, whereby the packed RNA density within SGs may give rise to additional 
regulatory effect between two proteins (139). In all, identifying the role of these $\mathrm{ZDBD}$-containing proteins in SGs and elucidating their interaction with respective binding partners are paramount towards better understanding of antiviral innate immunity.

\section{CONCLUSION}

To date, only six proteins $\left(A D A R 1_{\mathrm{p} 150}, \mathrm{ZBP} 1, \mathrm{E} 3 \mathrm{~L}, \mathrm{PKZ}, \mathrm{ORF}-\right.$ 112, and RBP7910) have been identified with $Z \alpha$ domain(s). Two common themes stood out among these proteins, where they are important in host-pathogen interaction, and they localize to SGs. The conservation of $Z \alpha$ domain in virus proteins is important for viral pathogenesis and immune evasion, but yet information on Z-DNA/Z-RNA motif within virus genomes is still sketchy. Similarly, while independent studies showed Z-RNA binding is responsible for protein localization to SGs, the bound substrate (Z-RNA) within SGs has not been elucidated. This is largely attributed to the transient nature when nucleic acids adapt Zconformation that could be dependent on the cellular environment. The condensed mRNA and protein aggregates in SGs may create a favourable environment for B-to-Z transition. Research studies using nucleic acid analogues that are prone to irreversible B-to-Z transition may afford a glimpse into understanding the precise mechanism at work (140).

Nonetheless, continuous research studies on individual ZDBD-containing proteins have ascertained the central role of Z $\alpha$ domain and Z-DNA/Z-RNA binding in pathogen and nonself-recognition. Current studies tend to focus on ZDBDcontaining proteins as a whole; instead, a reinvigorated appreciation on the key role of $Z \alpha$ domain in molecular innate immunity is warranted in future research. Research gaps remained; such as to understand the role of $\mathrm{Z} \alpha$-mediated localization to SGs, to address the possible redundancy between first and second $\mathrm{Z} \alpha$ domains, to determine how $\mathrm{Z} \alpha$

\section{REFERENCES}

1. Rich A, Zhang S. Z-DNA: the long road to biological function. Nat Rev Genet (2003) 4(7):566-72. doi: 10.1038/nrg1115

2. Rich A, Nordheim A, Wang AH-J. The Chemistry And Biology Of LeftHanded Z-DNA. Annu Rev Biochem (1984) 53(1):791-846. doi: 10.1146/ annurev.bi.53.070184.004043

3. Wang AH, Quigley GJ, Kolpak FJ, Crawford JL, van Boom JH, van der Marel $\mathrm{G}$, et al. Molecular structure of a left-handed double helical DNA fragment at atomic resolution. Nature (1979) 282:680-6. doi: 10.1038/282680a0

4. Herbert A, Schade M, Lowenhaupt K, Alfken J, Schwartz T, Shlyakhtenko LS, et al. The Z $\alpha$ domain from human ADAR1 binds to the Z-DNA conformer of many different sequences. Nucleic Acids Res (1998) 26 (15):3486-93. doi: 10.1093/nar/26.15.3486

5. Herbert A. Z-DNA and Z-RNA in human disease. Commun Biol (2019) 2 (1):7. doi: 10.1038/s42003-018-0237-x

6. Cho CJ, Myung SJ, Chang S. ADAR1 and MicroRNA; A Hidden Crosstalk in Cancer. Int J Mol Sci (2017) 18(4):799. doi: 10.3390/ijms18040799

7. Wang Z, Choi MK, Ban T, Yanai H, Negishi H, Lu Y, et al. Regulation of innate immune responses by DAI (DLM-1/ZBP1) and other DNA-sensing molecules. Proc Natl Acad Sci U S A (2008) 105(14):5477-82. doi: 10.1073/ pnas.0801295105 domain differentiate self from non-self-nucleic acids, and to resolve the seemingly contradictory function of $\mathrm{ZBP} 1$ and $\mathrm{ADAR} 1_{\mathrm{p} 150}$ during antiviral response. Taken together, $\mathrm{Z} \alpha$ mediated nucleic acid binding represents a significant but mysterious role in immunity, and may yet offer a highlyspecific Z-DNA/Z-RNA-based intervention towards immune regulation in the future.

\section{AUTHOR CONTRIBUTIONS}

DC, YL, and SKN conceived the framework for the manuscript. DC and SKN prepared the draft manuscript. DC, YL, and SKN revised and edited the final manuscript. All authors contributed to the article and approved the submitted version.

\section{FUNDING}

This work is supported under Research University Grant for Individual (1001/CIPPT/8012264) from Universiti Sains Malaysia. DC is a recipient of Penang Future Foundation Scholarship (1709/CP039). SKN is also funded by Fundamental Research Grant Scheme (203/CIPPT/6711566) from Ministry of Higher Education, Malaysia.

\section{ACKNOWLEDGMENTS}

We are extremely grateful for Jit Hong Tan for critical reading of the manuscript, and towards Shan Xiang Koh, Chin Yee Tan, Nur Nadia Che Aziz, and Alvin Paul for engaging discussions. We also thank the members of RNA-Bio Research Group, Advanced Medical and Dental Institute, Universiti Sains Malaysia, for their support and assistance.

8. Wu C, Hu Y, Fan L, Wang H, Sun Z, Deng S, et al. Ctenopharyngodon idella PKZ facilitates cell apoptosis through phosphorylating eIF2 $\alpha$. Mol Immunol (2016) 69:13-23. doi: 10.1016/j.molimm.2015.11.006

9. Hall K, Cruz P, Tinoco I, Jovin TM, van de Sande JH. 'Z-RNA'-a lefthanded RNA double helix. Nature (1984) 311(5986):584-6. doi: 10.1038/ $311584 \mathrm{a} 0$

10. Brown BA, Lowenhaupt K, Wilbert CM, Hanlon EB, Rich A. The Z $\alpha$ domain of the editing enzyme dsRNA adenosine deaminase binds left-handed ZRNA as well as Z-DNA. Proc Natl Acad Sci (2000) 97(25):13532-6. doi: 10.1073/pnas.240464097

11. Lee A-R, Hwang J, Hur JH, Ryu K-S, Kim KK, Choi B-S, et al. NMR Dynamics Study Reveals the Z $\alpha$ Domain of Human ADAR1 Associates with and Dissociates from Z-RNA More Slowly than Z-DNA. ACS Chem Biol (2019) 14(2):245-55. doi: 10.1021/acschembio.8b00914

12. Teng MK, Liaw YC, Van der Marel GA, Van Boom JH, Wang AHJ. Effects of the O2' hydroxyl group on Z-DNA conformation: structure of Z-RNA and (araC)-[Z-DNA]. Biochemistry (1989) 28(12):4923-8. doi: 10.1021/ bi00438a001

13. Schwartz T, Rould MA, Lowenhaupt K, Herbert A, Rich A. Crystal structure of the Zalpha domain of the human editing enzyme ADAR1 bound to lefthanded Z-DNA. Sci (New York NY) (1999) 284(5421):1841-5. doi: 10.1126/ science.284.5421.1841 
14. Wang Q, Li L, Wang X, Liu H, Yao X. Understanding the recognition mechanisms of $Z \alpha$ domain of human editing enzyme ADAR1 $(\mathrm{hZ} \alpha(\mathrm{ADAR} 1))$ and various $\mathrm{Z}$-DNAs from molecular dynamics simulation. J Mol Modeling (2014) 20(11):2500. doi: 10.1007/s00894-0142500-5

15. Schade M, Behlke J, Lowenhaupt K, Herbert A, Rich A. Oschkinat H. A 6 bp Z-DNA hairpin binds two $Z \alpha$ domains from the human RNA editing enzyme ADAR1. FEBS Lett (1999) 458(1):27-31. doi: 10.1016/S0014-5793 (99)01119-9

16. Ha SC, Choi J, Hwang HY, Rich A, Kim YG, Kim KK. The structures of nonCG-repeat Z-DNAs co-crystallized with the Z-DNA-binding domain, hZ alpha(ADAR1). Nucleic Acids Res (2009) 37(2):629-37. doi: 10.1093/nar/ gkn976

17. Schroth GP, Chou P-J, Ho PS. Mapping Z-DNA in the human genome. Computer-aided mapping reveals a nonrandom distribution of potential ZDNA-forming sequences in human genes. J Biol Chem (1992) 267 (17):11846-55. doi: 10.1016/S0021-9258(19)49776-7

18. Shin S-I, Ham S, Park J, Seo SH, Lim CH, Jeon H, et al. Z-DNA-forming sites identified by ChIP-Seq are associated with actively transcribed regions in the human genome. DNA Res (2016) 23(5):477-86. doi: 10.1093/dnares/dsw031

19. George CX, Samuel CE. Human RNA-specific adenosine deaminase ADAR1 transcripts possess alternative exon 1 structures that initiate from different promoters, one constitutively active and the other interferon inducible. Proc Natl Acad Sci (1999) 96(8):4621-6. doi: 10.1073/pnas.96.8.4621

20. Herbert A, Alfken J, Kim Y-G, Mian IS, Nishikura K, Rich A. A Z-DNA binding domain present in the human editing enzyme, double-stranded RNA adenosine deaminase. Proc Natl Acad Sci (1997) 94(16):8421-6. doi: 10.1073/pnas.94.16.8421

21. Schwartz T, Behlke J, Lowenhaupt K, Heinemann U, Rich A. Structure of the DLM-1-Z-DNA complex reveals a conserved family of Z-DNA-binding proteins. Nat Struct Biol (2001) 8(9):761-5. doi: 10.1038/nsb0901-761

22. Hu C-Y, Zhang Y-B, Huang G-P, Zhang Q-Y, Gui J-F. Molecular cloning and characterisation of a fish PKR-like gene from cultured CAB cells induced by UV-inactivated virus. Fish shellfish Immunol (2004) 17(4):35366. doi: 10.1016/j.fsi.2004.04.009

23. Ha SC, Lokanath NK, Van Quyen D, Wu CA, Lowenhaupt K, Rich A, et al. A poxvirus protein forms a complex with left-handed Z-DNA: crystal structure of a Yatapoxvirus Z $\alpha$ bound to DNA. Proc Natl Acad Sci (2004) 101 (40):14367-72. doi: 10.1073/pnas.0405586101

24. Kuś K, Rakus K, Boutier M, Tsigkri T, Gabriel L, Vanderplasschen A, et al. The Structure of the Cyprinid herpesvirus 3 ORF112-Z $\alpha$-Z-DNA Complex Reveals a Mechanism of Nucleic Acids Recognition Conserved with E3L, a Poxvirus Inhibitor of Interferon Response. J Biol Chem (2015) 290 (52):30713-25. doi: 10.1074/jbc.M115.679407

25. Nikpour N, Salavati R. The RNA binding activity of the first identified trypanosome protein with Z-DNA-binding domains. Sci Rep (2019) 9 (1):5904. doi: 10.1038/s41598-019-42409-1

26. Seth RB, Sun L, Chen ZJ. Antiviral innate immunity pathways. Cell Res (2006) 16(2):141-7. doi: 10.1038/sj.cr.7310019

27. Onomoto K, Yoneyama M, Fung G, Kato H, Fujita T. Antiviral innate immunity and stress granule responses. Trends Immunol (2014) 35(9):4208. doi: 10.1016/j.it.2014.07.006

28. Aoshi T, Koyama S, Kobiyama K, Akira S, Ishii KJ. Innate and adaptive immune responses to viral infection and vaccination. Curr Opin Virol (2011) 1(4):226-32. doi: 10.1016/j.coviro.2011.07.002

29. Chen J, Baig E, Fish EN. Diversity and Relatedness Among the Type I Interferons. J Interferon Cytokine Res (2004) 24(12):687-98. doi: 10.1089/ jir.2004.24.687

30. Roberts RM, Liu L, Guo Q, Leaman D, Bixby J. The Evolution of the Type I Interferons1. J Interferon Cytokine Res (1998) 18(10):805-16. doi: 10.1089/ jir.1998.18.805

31. Uzé G, Schreiber G, Piehler J, Pellegrini S. "The Receptor of the Type I Interferon Family". In: PM Pitha, editor. Interferon: The 50th Anniversary. Berlin, Heidelberg: Springer Berlin Heidelberg (2007). p. 71-95.

32. Yoneyama M, Fujita T. Recognition of viral nucleic acids in innate immunity. Rev Med Virol (2010) 20(1):4-22. doi: 10.1002/rmv.633

33. Paul A, Tang TH, Ng SK. Interferon Regulatory Factor 9 Structure and Regulation. Front Immunol (2018) 9(1831). doi: 10.3389/fimmu.2018.01831
34. Müller M, Laxton C, Briscoe J, Schindler C, Improta T, Darnell Jr JE, et al. Complementation of a mutant cell line: central role of the $91 \mathrm{kDa}$ polypeptide of ISGF3 in the interferon-alpha and -gamma signal transduction pathways. EMBO J (1993) 12(11):4221-8. doi: 10.1002/ j.1460-2075.1993.tb06106.x

35. Fink K, Grandvaux N. STAT2 and IRF9: Beyond ISGF3. JAKSTAT (2013) 2 (4):e27521. doi: 10.4161/jkst.27521

36. Schneider WM, Chevillotte MD, Rice CM. Interferon-Stimulated Genes: A Complex Web of Host Defenses. Annu Rev Immunol (2014) 32(1):513-45. doi: 10.1146/annurev-immunol-032713-120231

37. Schoggins JW. Interferon-Stimulated Genes: What Do They All Do? Annu Rev Virol (2019) 6(1):567-84. doi: 10.1146/annurev-virology-092818015756

38. Stetson DB, Medzhitov R. Type I Interferons in Host Defense. Immunity (2006) 25(3):373-81. doi: 10.1016/j.immuni.2006.08.007

39. Hofmann S, Kedersha N, Anderson P, Ivanov P. Molecular mechanisms of stress granule assembly and disassembly. Biochim Biophys Acta (BBA) - Mol Cell Res (2021) 1868(1):118876. doi: 10.1016/j.bbamcr.2020. 118876

40. McCormick C, Khaperskyy DA. Translation inhibition and stress granules in the antiviral immune response. Nat Rev Immunol (2017) 17(10):647-60. doi: 10.1038/nri.2017.63

41. Panas MD, Ivanov P, Anderson P. Mechanistic insights into mammalian stress granule dynamics. J Cell Biol (2016) 215(3):313-23. doi: 10.1083/ jcb.201609081

42. Zhang K, Daigle JG, Cunningham KM, Coyne AN, Ruan K, Grima JC, et al. Stress Granule Assembly Disrupts Nucleocytoplasmic Transport. Cell (2018) 173(4):958-71.e17. doi: 10.1016/j.cell.2018.03.025

43. Anderson P, Kedersha N. Stress granules: the Tao of RNA triage. Trends Biochem Sci (2008) 33(3):141-50. doi: 10.1016/j.tibs.2007.12.003

44. Mahboubi H, Stochaj U. Cytoplasmic stress granules: Dynamic modulators of cell signaling and disease. Biochim Biophys Acta (BBA) - Mol Basis Dis (2017) 1863(4):884-95. doi: 10.1016/j.bbadis.2016.12.022

45. Kedersha N, Ivanov P, Anderson P. Stress granules and cell signaling: more than just a passing phase? Trends Biochem Sci (2013) 38(10):494-506. doi: 10.1016/j.tibs.2013.07.004

46. Eiermann N, Haneke K, Sun Z, Stoecklin G, Ruggieri A. Dance with the Devil: Stress Granules and Signaling in Antiviral Responses. Viruses (2020) 12(9):984. doi: 10.3390/v12090984

47. Nunes C, Mestre I, Marcelo A, Koppenol R, Matos CA, Nóbrega C. MSGP: the first database of the protein components of the mammalian stress granules. Database (2019) 2019:31. doi: 10.1093/database/baz031

48. Youn J-Y, Dyakov BJA, Zhang J, Knight JDR, Vernon RM, Forman-Kay JD, et al. Properties of Stress Granule and P-Body Proteomes. Mol Cell (2019) 76 (2):286-94. doi: 10.1016/j.molcel.2019.09.014

49. Wheeler JR, Matheny T, Jain S, Abrisch R, Parker R. Distinct stages in stress granule assembly and disassembly. eLife (2016) 5:e18413. doi: 10.7554/ eLife. 18413

50. Kedersha N, Chen S, Gilks N, Li W, Miller IJ, Stahl J, et al. Evidence that ternary complex (eIF2-GTP-tRNA(i)(Met))-deficient preinitiation complexes are core constituents of mammalian stress granules. Mol Biol Cell (2002) 13(1):195-210. doi: 10.1091/mbc.01-05-0221

51. Anderson P, Kedersha N. Stress granules. Curr Biol (2009) 19(10):R397-R8. doi: 10.1016/j.cub.2009.03.013

52. Zhang Q, Sharma NR, Zheng Z-M, Chen M. Viral Regulation of RNA Granules in Infected Cells. Virologica Sin (2019) 34(2):175-91. doi: 10.1007/ s12250-019-00122-3

53. White JP, Cardenas AM, Marissen WE, Lloyd RE. Inhibition of cytoplasmic mRNA stress granule formation by a viral proteinase. Cell host Microbe (2007) 2(5):295-305. doi: 10.1016/j.chom.2007.08.006

54. Nakagawa K, Narayanan K, Wada M, Makino S. Inhibition of Stress Granule Formation by Middle East Respiratory Syndrome Coronavirus 4a Accessory Protein Facilitates Viral Translation, Leading to Efficient Virus Replication. J Virol (2018) 92(20):e00902-18. doi: 10.1128/jvi.00902-18

55. Nelson EV, Schmidt KM, Deflubé LR, Doğanay S, Banadyga L, Olejnik J, et al. Ebola Virus Does Not Induce Stress Granule Formation during Infection and Sequesters Stress Granule Proteins within Viral Inclusions. J Virol (2016) 90(16):7268. doi: 10.1128/JVI.00459-16 
56. Bonenfant G, Williams N, Netzband R, Schwarz MC, Evans MJ, Pager CT. Zika Virus Subverts Stress Granules To Promote and Restrict Viral Gene Expression. J Virol (2019) 93(12):e00520-19. doi: 10.1128/jvi. 00520-19

57. Sun Y, Dong L, Yu S, Wang X, Zheng H, Zhang P, et al. Newcastle disease virus induces stable formation of bona fide stress granules to facilitate viral replication through manipulating host protein translation. FASEB J (2017) 31(4):1482-93. doi: 10.1096/fj.201600980R

58. Yang X, Hu Z, Fan S, Zhang Q, Zhong Y, Guo D, et al. Picornavirus $2 \mathrm{~A}$ protease regulates stress granule formation to facilitate viral translation. PLoS Pathog (2018) 14(2):e1006901. doi: 10.1371/journal.ppat.1006901

59. Savva YA, Rieder LE, Reenan RA. The ADAR protein family. Genome Biol (2012) 13(12):252. doi: 10.1186/gb-2012-13-12-252

60. Špačková N, Réblová K. Role of Inosine-Uracil Base Pairs in the Canonical RNA Duplexes. Genes (2018) 9(7):324. doi: 10.3390/genes9070324

61. Xu LD, Öhman M. ADAR1 Editing and its Role in Cancer. Genes (2018) 10 (1):12. doi: 10.3390/genes10010012

62. Chan TH, Qamra A, Tan KT, Guo J, Yang H, Qi L, et al. ADAR-Mediated RNA Editing Predicts Progression and Prognosis of Gastric Cancer. Gastroenterology (2016) 151(4):637-50.e10. doi: 10.1053/ j.gastro.2016.06.043

63. Chen Y, Wang H, Lin W, Shuai P. ADAR1 overexpression is associated with cervical cancer progression and angiogenesis. Diagn Pathol (2017) 12(1):12. doi: 10.1186/s13000-017-0600-0

64. Sagredo EA, Blanco A, Sagredo AI, Pérez P, Sepúlveda-Hermosilla G, Morales F, et al. ADAR1-mediated RNA-editing of $3^{\prime} \mathrm{UTR}$ in breast cancer. Biol Res (2018) 51(1):36. doi: 10.1186/s40659-018-0185-4

65. Ramírez-Moya J, Baker AR, Slack FJ, Santisteban P. ADAR1-mediated RNA editing is a novel oncogenic process in thyroid cancer and regulates miR-200 activity. Oncogene (2020) 39(18):3738-53. doi: 10.1038/s41388-020-1248-x

66. Li Y, Chen L, Chan TH, Guan XY. Hepatocellular carcinoma: transcriptome diversity regulated by RNA editing. Int J Biochem Cell Biol (2013) 45 (8):1843-8. doi: 10.1016/j.biocel.2013.05.033

67. Wang W, Xie Y, Chen F, Liu X, Zhong LL, Wang HQ, et al. LncRNA MEG3 acts a biomarker and regulates cell functions by targeting ADAR1 in colorectal cancer. World J Gastroenterol (2019) 25(29):3972-84. doi: $10.3748 /$ wjg.v25.i29.3972

68. Eckmann CR, Neunteufl A, Pfaffstetter L, Jantsch MF. The human but not the Xenopus RNA-editing enzyme ADAR1 has an atypical nuclear localization signal and displays the characteristics of a shuttling protein. Mol Biol Cell (2001) 12(7):1911-24. doi: 10.1091/mbc.12.7.1911

69. Nie Y, Zhao Q, Su Y, Yang J-H. Subcellular distribution of ADAR1 isoforms is synergistically determined by three nuclear discrimination signals and a regulatory motif. J Biol Chem (2004) 279(13):13249-55. doi: 10.1074/ jbc.m312753200

70. Poulsen H, Nilsson J, Damgaard CK, Egebjerg J, Kjems J. CRM1 mediates the export of ADAR1 through a nuclear export signal within the Z-DNA binding domain. Mol Cell Biol (2001) 21(22):7862-71. doi: 10.1128/ mcb.21.22.7862-7871.2001

71. Liddicoat BJ, Chalk AM, Walkley CR. ADAR1, inosine and the immune sensing system: distinguishing self from non-self. Wiley Interdiscip Rev RNA (2016) 7(2):157-72. doi: 10.1002/wrna.1322

72. Song C, Sakurai M, Shiromoto Y, Nishikura K. Functions of the RNA Editing Enzyme ADAR1 and Their Relevance to Human Diseases. Genes (2016) 7 (12):129. doi: 10.3390/genes7120129

73. Lamers MM, van den Hoogen BG, Haagmans BL. ADAR1: "Editor-inChief” of Cytoplasmic Innate Immunity. Front Immunol (2019) 10:1763. doi: 10.3389/fimmu.2019.01763

74. Pestal K, Funk CC, Snyder JM, Price ND, Treuting PM, Stetson DB. Isoforms of RNA-Editing Enzyme ADAR1 Independently Control Nucleic Acid Sensor MDA5-Driven Autoimmunity and Multi-organ Development. Immunity (2015) 43(5):933-44. doi: 10.1016/j.immuni.2015.11.001

75. Ben-Shoshan SO, Kagan P, Sultan M, Barabash Z, Dor C, Jacob-Hirsch J, et al. ADAR1 deletion induces NFKB and interferon signaling dependent liver inflammation and fibrosis. RNA Biol (2017) 14(5):587-602. doi: $10.1080 / 15476286.2016 .1203501$

76. Wang Y, Men M, Xie B, Shan J, Wang C, Liu J, et al. Inhibition of PKR protects against $\mathrm{H} 2 \mathrm{O} 2$-induced injury on neonatal cardiac myocytes by attenuating apoptosis and inflammation. Sci Rep (2016) 6(1):38753. doi: 10.1038/srep38753

77. Chung H, Calis JJA, Wu X, Sun T, Yu Y, Sarbanes SL, et al. Human ADAR1 Prevents Endogenous RNA from Triggering Translational Shutdown. Cell (2018) 172(4):811-24.e14. doi: 10.1016/j.cell.2017.12.038

78. Ahmad S, Mu X, Yang F, Greenwald E, Park JW, Jacob E, et al. Breaching Self-Tolerance to Alu Duplex RNA Underlies MDA5-Mediated Inflammation. Cell (2018) 172(4):797-810.e13. doi: 10.1016/ j.cell.2017.12.016

79. Samuel CE. Adenosine deaminases acting on RNA (ADARs) are both antiviral and proviral. Virology (2011) 411(2):180-93. doi: 10.1016/ j.virol.2010.12.004

80. Pujantell M, Franco S, Galván-Femenía I, Badia R, Castellví M, Garcia-Vidal E, et al. ADAR1 affects HCV infection by modulating innate immune response. Antiviral Res (2018) 156:116-27. doi: 10.1016/ j.antiviral.2018.05.012

81. Liu G, Ma X, Wang Z, Wakae K, Yuan Y, He Z, et al. Adenosine deaminase acting on RNA-1 (ADAR1) inhibits hepatitis B virus (HBV) replication by enhancing microRNA-122 processing. J Biol Chem (2019) 294(38):1404354. doi: $10.1074 /$ jbc.RA119.007970

82. Samuel CE. Adenosine deaminase acting on RNA (ADAR1), a suppressor of double-stranded RNA-triggered innate immune responses. I Biol Chem (2019) 294(5):1710-20. doi: 10.1074/jbc.TM118.004166

83. Li Z, Okonski KM, Samuel CE. Adenosine Deaminase Acting on RNA 1 (ADAR1) Suppresses the Induction of Interferon by Measles Virus. J Virol (2012) 86(7):3787-94. doi: 10.1128/jvi.06307-11

84. Casey JL. Control of ADAR1 editing of hepatitis delta virus RNAs. Curr topics Microbiol Immunol (2012) 353:123-43. doi: 10.1007/82_2011_146

85. Radetskyy R, Daher A, Gatignol A. ADAR1 and PKR, interferon stimulated genes with clashing effects on HIV-1 replication. Cytokine Growth factor Rev (2018) 40:48-58. doi: 10.1016/j.cytogfr.2018.03.007

86. Zhang H, Ni G, Damania B. ADAR1 Facilitates KSHV Lytic Reactivation by Modulating the RLR-Dependent Signaling Pathway. Cell Rep (2020) 31 (4):107564. doi: 10.1016/j.celrep.2020.107564

87. Cachat A, Alais S, Chevalier SA, Journo C, Fusil F, Dutartre H, et al. ADAR1 enhances HTLV-1 and HTLV-2 replication through inhibition of PKR activity. Retrovirology (2014) 11(1):93. doi: 10.1186/s12977-0140093-9

88. Diosa-Toro M, Echavarría-Consuegra L, Flipse J, Fernández GJ, Kluiver J, van den Berg A, et al. MicroRNA profiling of human primary macrophages exposed to dengue virus identifies miRNA-3614-5p as antiviral and regulator of ADAR1 expression. PLoS neglected Trop Dis (2017) 11(10): e0005981. doi: 10.1371/journal.pntd.0005981

89. Herbert A. Mendelian disease caused by variants affecting recognition of ZDNA and Z-RNA by the Z $\alpha$ domain of the double-stranded RNA editing enzyme ADAR. Eur J Hum Genet EJHG (2020) 28(1):114-7. doi: 10.1038/ s41431-019-0458-6

90. Weissbach R, Scadden A. Tudor-SN and ADAR1 are components of cytoplasmic stress granules. RNA (New York NY) (2012) 18(3):462-71. doi: $10.1261 /$ rna.027656.111

91. Ng SK, Weissbach R, Ronson GE, Scadden AD. Proteins that contain a functional Z-DNA-binding domain localize to cytoplasmic stress granules. Nucleic Acids Res (2013) 41(21):9786-99. doi: 10.1093/nar/gkt750

92. Feng S, Li H, Zhao J, Pervushin K, Lowenhaupt K, Schwartz TU, et al. Alternate rRNA secondary structures as regulators of translation. Nat Struct Mol Biol (2011) 18(2):169-76. doi: 10.1038/nsmb.1962

93. John L, Samuel CE. Induction of stress granules by interferon and downregulation by the cellular RNA adenosine deaminase ADAR1. Virology (2014) 454-455:299-310. doi: 10.1016/j.virol.2014.02.025

94. Koeris M, Funke L, Shrestha J, Rich A, Maas S. Modulation of ADAR1 editing activity by Z-RNA in vitro. Nucleic Acids Res (2005) 33(16):5362-70. doi: $10.1093 /$ nar/gki849

95. Kuriakose T, Kanneganti T-D. ZBP1: Innate Sensor Regulating Cell Death and Inflammation. Trends Immunol (2018) 39(2):123-34. doi: 10.1016/ j.it.2017.11.002

96. Ingram JP, Thapa RJ, Fisher A, Tummers B, Zhang T, Yin C, et al. ZBP1/ DAI Drives RIPK3-Mediated Cell Death Induced by IFNs in the Absence of RIPK1. J Immunol (2019) 203(5):1348-55. doi: 10.4049/jimmunol.1900216 
97. Malireddi RKS, Kesavardhana S, Kanneganti TD. ZBP1 and TAK1: Master Regulators of NLRP3 Inflammasome/Pyroptosis, Apoptosis, and Necroptosis (PAN-optosis). Front Cell Infect Microbiol (2019) 9:406. doi: 10.3389/fcimb.2019.00406

98. Yang D, Liang Y, Zhao S, Ding Y, Zhuang Q, Shi Q, et al. ZBP1 mediates interferon-induced necroptosis. Cell Mol Immunol (2020) 17(4):356-68. doi: 10.1038/s41423-019-0237-x

99. Kuriakose T, Man SM, Malireddi RKS, Karki R, Kesavardhana S, Place DE, et al. ZBP1/DAI is an innate sensor of influenza virus triggering the NLRP3 inflammasome and programmed cell death pathways. Sci Immunol (2016) 1 (2):aag2045. doi: 10.1126/sciimmunol.aag2045

100. Rothan HA, Arora K, Natekar JP, Strate PG, Brinton MA, Kumar M. ZDNA-Binding Protein 1 Is Critical for Controlling Virus Replication and Survival in West Nile Virus Encephalitis. Front Microbiol (2019) 10:2089. doi: 10.3389/fmicb.2019.02089

101. Devos M, Tanghe G, Gilbert B, Dierick E, Verheirstraeten M, Nemegeer J, et al. Sensing of endogenous nucleic acids by ZBP1 induces keratinocyte necroptosis and skin inflammation. J Exp Med (2020) 217(7):e20191913. doi: 10.1084/jem.20191913

102. Zhao S, Xie L, Wangt Z, Wang J, Hu H, Hang X, et al. ZBP1 (DAI/DLM-1) promotes osteogenic differentiation while inhibiting adipogenic differentiation in mesenchymal stem cells through a positive feedback loop of Wnt/B-catenin signaling. Bone Res (2020) 8(1):12. doi: 10.1038/s41413020-0085-4

103. Ha SC, Van Quyen D, Hwang HY, Oh DB, Brown BA,2, Lee SM, et al. Biochemical characterization and preliminary X-ray crystallographic study of the domains of human ZBP1 bound to left-handed Z-DNA. Biochim Biophys Acta (2006) 1764(2):320-3. doi: 10.1016/j.bbapap. 2005.12.012

104. Deigendesch N, Koch-Nolte F, Rothenburg S. ZBP1 subcellular localization and association with stress granules is controlled by its ZDNA binding domains. Nucleic Acids Res (2006) 34(18):5007-20. doi: 10.1093/nar/gkl575

105. Zhang T, Yin C, Boyd DF, Quarato G, Ingram JP, Shubina M, et al. Influenza Virus Z-RNAs Induce ZBP1-Mediated Necroptosis. Cell (2020) 180 (6):1115-29.e13. doi: 10.1016/j.cell.2020.02.050

106. Kesavardhana S, Subbarao Malireddi RK, Burton AR, Porter SN, Vogel P, Pruett-Miller SM, et al. Zo2 domain of ZBP1 is a molecular switch regulating Influenza-induced PANoptosis and perinatal lethality during development. J Biol Chem (2020) 295(24):8325-30. doi: 10.1074/ jbc.RA120.013752

107. Guo H, Gilley RP, Fisher A, Lane R, Landsteiner VJ, Ragan KB, et al. Speciesindependent contribution of ZBP1/DAI/DLM-1-triggered necroptosis in host defense against HSV1. Cell Death Dis (2018) 9(8):816. doi: 10.1038/ s41419-018-0868-3

108. Myskiw C, Arsenio J, van Bruggen R, Deschambault Y, Cao J. Vaccinia Virus E3 Suppresses Expression of Diverse Cytokines through Inhibition of the PKR, NF-KB, and IRF3 Pathways. J Virol (2009) 83(13):6757-68. doi: 10.1128/jvi.02570-08

109. Smith EJ, Marié I, Prakash A, García-Sastre A, Levy DE. IRF3 and IRF7 phosphorylation in virus-infected cells does not require double-stranded RNA-dependent protein kinase R or Ikappa B kinase but is blocked by Vaccinia virus E3L protein. J Biol Chem (2001) 276(12):8951-7. doi: 10.1074/ jbc.M008717200

110. Dueck KJ, Hu YS, Chen P, Deschambault Y, Lee J, Varga J, et al. Mutational analysis of vaccinia virus $\mathrm{E} 3$ protein: the biological functions do not correlate with its biochemical capacity to bind double-stranded RNA. J Virol (2015) 89 (10):5382-94. doi: 10.1128/jvi.03288-14

111. Guerra S, Cáceres A, Knobeloch KP, Horak I, Esteban M. Vaccinia virus E3 protein prevents the antiviral action of ISG15. PLoS Pathog (2008) 4(7): e1000096. doi: 10.1371/journal.ppat.1000096

112. White SD, Jacobs BL. The amino terminus of the vaccinia virus E3 protein is necessary to inhibit the interferon response. J Virol (2012) 86(10):5895-904. doi: 10.1128/jvi.06889-11

113. Langland JO, Jacobs BL. Inhibition of PKR by vaccinia virus: role of the Nand C-terminal domains of E3L. Virology (2004) 324(2):419-29. doi: 10.1016/j.virol.2004.03.012
114. Kim YG, Muralinath M, Brandt T, Pearcy M, Hauns K, Lowenhaupt K, et al. A role for Z-DNA binding in vaccinia virus pathogenesis. Proc Natl Acad Sci U S A (2003) 100(12):6974-9. doi: 10.1073/pnas.0431131100

115. Cao H, Dai P, Wang W, Li H, Yuan J, Wang F, et al. Innate immune response of human plasmacytoid dendritic cells to poxvirus infection is subverted by vaccinia E3 via its Z-DNA/RNA binding domain. PLoS One (2012) 7(5): e36823. doi: 10.1371/journal.pone.0036823

116. Koehler H, Cotsmire S, Langland J, Kibler KV, Kalman D, Upton JW, et al. Inhibition of DAI-dependent necroptosis by the Z-DNA binding domain of the vaccinia virus innate immune evasion protein, E3. Proc Natl Acad Sci U S A (2017) 114(43):11506-11. doi: 10.1073/pnas.1700999114

117. Simpson-Holley M, Kedersha N, Dower K, Rubins KH, Anderson P, Hensley LE, et al. Formation of antiviral cytoplasmic granules during orthopoxvirus infection. J Virol (2011) 85(4):1581-93. doi: 10.1128/jvi.02247-10

118. Wu C, Zhang Y, Hu C. PKZ, a Fish-Unique eIF2 $\alpha$ Kinase Involved in Innate Immune Response. Front Immunol (2020) 11:585. doi: 10.3389/ fimmu.2020.00585

119. Rothenburg S, Deigendesch N, Dittmar K, Koch-Nolte F, Haag F, Lowenhaupt $\mathrm{K}$, et al. A PKR-like eukaryotic initiation factor $2 \alpha$ kinase from zebrafish contains Z-DNA binding domains instead of dsRNA binding domains. Proc Natl Acad Sci U S A (2005) 102(5):1602-7. doi: 10.1073/ pnas.0408714102

120. Zhang Y, Zhang Q, Xu D, Hu C, Gui J. Identification of antiviral-relevant genes in the cultured fish cells induced by UV-inactivated virus. Chin Sci Bull (2003) 48(6):581-8. doi: 10.1360/03tb9124

121. Liu TK, Zhang YB, Liu Y, Sun F, Gui JF. Cooperative roles of fish protein kinase containing Z-DNA binding domains and double-stranded RNAdependent protein kinase in interferon-mediated antiviral response. J Virol (2011) 85(23):12769-80. doi: 10.1128/jvi.05849-11

122. Rothenburg S, Deigendesch N, Dey M, Dever TE, Tazi L. Double-stranded RNA-activated protein kinase PKR of fishes and amphibians: varying the number of double-stranded RNA binding domains and lineage-specific duplications. BMC Biol (2008) 6:12. doi: 10.1186/1741-7007-6-12

123. Xu X, Li M, Wu C, Li D, Jiang Z, Liu C, et al. The Fish-Specific Protein Kinase (PKZ) Initiates Innate Immune Responses via IRF3- and ISGF3-Like Mediated Pathways. Front Immunol (2019) 10:582. doi: 10.3389/ fimmu.2019.00582

124. Yang P-J, Wu C-X, Li W, Fan L-H, Lin G, Hu C-Y. Cloning and functional analysis of PKZ (PKR-like) from grass carp (Ctenopharyngodon idellus). Fish Shellfish Immunol (2011) 31(6):1173-8. doi: 10.1016/j.fsi.2011.10.012

125. Kim D, Hur J, Park K, Bae S, Shin D, Ha SC, et al. Distinct Z-DNA binding mode of a PKR-like protein kinase containing a Z-DNA binding domain (PKZ). Nucleic Acids Res (2014) 42(9):5937-48. doi: 10.1093/nar/gkul89

126. de Rosa M, Zacarias S, Athanasiadis A. Structural basis for Z-DNA binding and stabilization by the zebrafish Z-DNA dependent protein kinase PKZ. Nucleic Acids Res (2013) 41(21):9924-33. doi: 10.1093/nar/gkt743

127. Kim D, Hwang HY, Kim YG, Kim KK. Crystallization and preliminary X-ray crystallographic studies of the Z-DNA-binding domain of a PKR-like kinase (PKZ) in complex with Z-DNA. Acta Crystallographica Section F Struct Biol Crystallization Commun (2009) 65(Pt 3):267-70. doi: 10.1107/ s1744309109002504

128. Tomé AR, Kuś K, Correia S, Paulo LM, Zacarias S, de Rosa M, et al. Crystal Structure of a Poxvirus-Like Zalpha Domain from Cyprinid Herpesvirus 3. J Virol (2013) 87(7):3998-4004. doi: 10.1128/jvi.03116-12

129. Adamek M, Matras M, Dawson A, Piackova V, Gela D, Kocour M, et al. Type I interferon responses of common carp strains with different levels of resistance to koi herpesvirus disease during infection with CyHV-3 or SVCV. Fish Shellfish Immunol (2019) 87:809-19. doi: 10.1016/j.fsi.2019.02.022

130. Gazestani VH, Nikpour N, Mehta V, Najafabadi HS, Moshiri H, Jardim A, et al. A Protein Complex Map of Trypanosoma brucei. PLoS neglected Trop Dis (2016) 10(3):e0004533. doi: 10.1371/journal.pntd.0004533

131. Rengachari S, Groiss S, Devos JM, Caron E, Grandvaux N, Panne D. Structural basis of STAT2 recognition by IRF9 reveals molecular insights into ISGF3 function. Proc Natl Acad Sci U S A (2018) 115(4):E601-E9. doi: $10.1073 /$ pnas. 1718426115

132. Kuriakose T, Zheng M, Neale G, Kanneganti TD. IRF1 Is a Transcriptional Regulator of ZBP1 Promoting NLRP3 Inflammasome Activation and Cell 
Death during Influenza Virus Infection. J Immunol (Baltimore Md 1950) (2018) 200(4):1489-95. doi: 10.4049/jimmunol.1701538

133. Liu D, Mao H, Gu M, Xu X, Sun Z, Lin G, et al. The transcription regulation analysis of Ctenopharyngodon idellus PKR and PKZ genes. Gene (2016) 576 (1, Part 3):512-9. doi: 10.1016/j.gene.2015.10.070

134. Bae S, Kim D, Kim KK, Kim Y-G, Hohng S. Intrinsic Z-DNA Is Stabilized by the Conformational Selection Mechanism of Z-DNA-Binding Proteins. J Am Chem Soc (2011) 133(4):668-71. doi: 10.1021/ja107498y

135. Ishiguro S, Galipon J, Ishii R, Suzuki Y, Kondo S, Okada-Hatakeyama M, et al. Base-pairing probability in the microRNA stem region affects the binding and editing specificity of human A-to-I editing enzymes ADAR1p110 and ADAR2. RNA Biol (2018) 15(7):976-89. doi: 10.1080/ 15476286.2018 .1486658

136. Osenberg S, Dominissini D, Rechavi G, Eisenberg E. Widespread cleavage of A-to-I hyperediting substrates. RNA (New York NY) (2009) 15(9):1632-9. doi: 10.1261/rna.1581809

137. Vitali P, Scadden ADJ. Double-stranded RNAs containing multiple IU pairs are sufficient to suppress interferon induction and apoptosis. Nat Struct Mol Biol (2010) 17(9):1043-50. doi: 10.1038/nsmb.1864

138. D'Ascenzo L, Leonarski F, Vicens Q, Auffinger P. 'Z-DNA like' fragments in RNA: a recurring structural motif with implications for folding, RNA/ protein recognition and immune response. Nucleic Acids Res (2016) 44 (12):5944-56. doi: 10.1093/nar/gkw388

139. Clerzius G, Gélinas J-F, Daher A, Bonnet M, Meurs EF, Gatignol A. ADAR1 Interacts with PKR during Human Immunodeficiency Virus Infection of Lymphocytes and Contributes to Viral Replication. J Virol (2009) 83 (19):10119-28. doi: 10.1128/jvi.02457-08

140. Zhang Y, Cui Y, An R, Liang X, Li Q, Wang H, et al. Topologically Constrained Formation of Stable Z-DNA from Normal Sequence under Physiological Conditions. J Am Chem Soc (2019) 141(19):7758-64. doi: $10.1021 /$ jacs. 8 b 13855

Conflict of Interest: The authors declare that the research was conducted in the absence of any commercial or financial relationships that could be construed as a potential conflict of interest.

Copyright $\odot 2021$ Chiang, Li and Ng. This is an open-access article distributed under the terms of the Creative Commons Attribution License (CC BY). The use, distribution or reproduction in other forums is permitted, provided the original author(s) and the copyright owner(s) are credited and that the original publication in this journal is cited, in accordance with accepted academic practice. No use, distribution or reproduction is permitted which does not comply with these terms. 